\title{
Framework for Computer Aided Education and Training for Hearing Impaired Learners
}

\author{
Jacob Oloo \\ Department of Computing \\ SCIT \\ Jomo Kenyatta University of \\ Agriculture and Technology
}

\author{
George Okeyo \\ Department of Computing \\ SCIT \\ Jomo Kenyatta University of \\ Agriculture and Technology
}

\author{
Wilson Cheruiyot \\ Department of Computing \\ SCIT \\ Jomo Kenyatta University of \\ Agriculture and Technology
}

\begin{abstract}
Information and Communication Technology (ICT) is a central aspect of modern life. Engagement with some educational, employment and social opportunities is dependent upon being able to make use of computers and the internet. For Disabled People especially those with hearing impairment, these opportunities can be particularly important. Learners with hearing impairment are given less attention in the world of technology. Most of the teachers who teach people with hearing impairment are not well informed on how to use computer and computer related accessories and peripherals. This is why integrating ICT with education for people with hearing impairment is always a challenge in most schools in Kenya. The study aims at enhancing the learning understandability of learners with hearing impairment using ICT. There are many people who are disabled but this study only focused on learners with hearing impairment in Kenya. This framework is mainly developed for deaf learners and educators of deaf learners. The framework was developed using Assistive technology. Two key categories of Assistive technology were used: KSL gesture recognition system and KSL computer aided learning and training tool.
\end{abstract}

\section{Keywords}

Disabled, Assistive technology, hearing Impairment, ICT in Education, Understandability.

\section{INTRODUCTION}

\subsection{Background}

Reading is listening with eyes, Listening is reading with ears. A deaf child is locked out of the latter. Education is a key factor in social, cultural, political and economic development of any nation. The first language a deaf child understands is Sign Language. Here in Kenya we refer to it as Kenya Sign Language (KSL) and this is the Language deaf learners are taught in to improve their literacy rate. Most deaf schools in Kenya still use the old traditional method of hand signs to teach the deaf learners yet ICT can offer a better alternative. According to the study carried out by Nickson O. Kakiri of Kenya National federation of deaf in 2012, he discovered that ICT teachers lack basic sign language and deaf culture knowledge. When there are opportunities for education, hearing children gets first priority, and if in special schools, boys usually receive them $\&$ not girls. This result into lesser use of ICT. Lack of professional interpreters for ICT related environment is a big challenge for learners with hearing impairment. Most effective forms of ICT to use with deaf learners are highly visual (such as images and animations) rather than reliant on written texts or sound. Hearing impaired learners also have speech disorders. Literally, deaf learners are untrained readers and get bored quickly therefore the usage of ICT related devices, images and animations become vital to keep their attention high.

\subsection{Scope of the Study}

This study mainly focused on the schools with disabled learners especially those with hearing impairment. The study investigated the existing computer aided systems for learners with hearing impairment, current research findings on how such learners use computer systems and recommends how to improve state of use. The study focused on schools in western province of Kenya and KISE College in Nairobi. The study examined framework formulation of computer aided education and training for hearing impaired learners. The research involved categories of respondents: teachers and learners with hearing impairment.

The rest of this paper is organized as follows: Related work, methodology, analysis, proposed framework for computer aided education and training for hearing impaired learners, framework validation, conclusion and future work.

\section{RELATED WORKS}

Chee Kyun (2008) proposed an E-Learning framework that creates a common platform for both normal and disabled students which will share the same influential of their academic achievement. The deaf students can communicate with instructor and other students by messaging over the chatroom system.

To encourage the deaf children to learn American Sign Language (ASL), Shirali-Shahreza (2008) proposed a system which is implemented using PHP scripting language. When a deaf person wants to enter a website which is created for deaf persons, a word is shown as a movie using SL. The user should recognize the word and select it from a list. If the user understands the SL and recognizes the word, he/she can enter the website.

Nicoletta \& Martin (2004) proposed a system which is an interactive program to teach ASL for K-3 mathematics by 3D animation.

In educational circle, hearing, seeing and doing play important role in achieving specific lesson objective. The ICT facilities provide the learners with opportunities to make learning more enjoyable because of the capabilities of the facilities.

\section{METHODOLOGY}

\subsection{Area of Study}

The study was conducted in western province of Kenya and KISE College in Nairobi. Western province consists of four Counties namely: Busia, Bungoma, Kakamega and Vihiga. 


\subsection{Population}

By 2011 western province of Kenya had 12 special education schools and units offering primary education to learners with hearing impairment. The enrolment of these schools was 713 children with hearing impairment. This research focused on these 12 schools. The study involved 2 teachers from each school of deaf learners.

\subsection{Data Collection}

Data collection was done in two stages. The first stage mainly involved collection of required data to develop the framework. The second stage aimed at evaluating and checking the effectiveness of the developed framework for computer aided education for hearing impaired learners. Tools used for data collection were questionnaires and interview schedules. The questionnaires were prepared for teachers. Interview schedule were prepared for learners with hearing impairment.

\subsubsection{Teachers' Questionnaire}

The teachers' questionnaire was used to collect data on their level of ICT competent, challenges they face using ICT devices, challenges learners with hearing impairment face when exposed to computers and other ICT devices, information about ICT in school, methods they use to teach their learners, proposed solutions to challenges learners face with ICT and the kind of framework they think is appropriate for computer aided learning for learners with hearing impairment.

\subsubsection{Pupils' interview schedule}

The pupils' interview schedule was used to collect information on the challenges learners with hearing impairment face when exposed to computers and what they think about ICT integration in their education.

\section{ANALYSIS}

\subsection{Kenya Institute of Special Education (KISE) College Case}

\subsubsection{How computers are used in the college}

The research revealed that Lecturers and teachers use these computers mainly for academic purpose such as research, assignments, communication, planning, administrative purpose and entertainment. A total of 40 students, 15 lecturers and 5 administrators were randomly sampled to fill the questionnaires at KISE. The summary of the analysis is as shown in the table and graph below.

Table 1. Distribution Table showing Computer use at KISE

\begin{tabular}{|c|c|c|c|}
\hline & \multicolumn{3}{|c|}{ Distribution (\%age) } \\
\hline Usage & Students & Lecturers & Administrators \\
\hline Research & 100 & 95 & 10 \\
\hline Assignment & 96 & 5 & 1 \\
\hline Communication & 55 & 47 & 50 \\
\hline Planning & 2 & 21 & 96 \\
\hline Entertainment & 100 & 36 & 10 \\
\hline Teaching & 20 & 80 & 2 \\
\hline
\end{tabular}

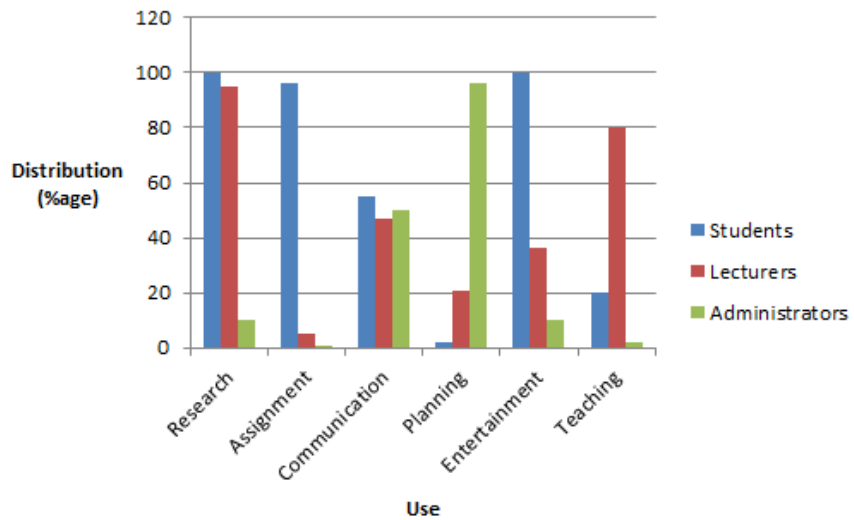

Figure 1. Graphical representation of computer use at KISE

\subsubsection{Opinion from College}

This study captured opinion from students and lecturers concerning computer aided education for the deaf. Majority of them said it would be a great idea to involve deaf learners in the current technology such that they are not left behind. Most lecturers and students said it would be a great idea to first introduce computer aided education for the deaf in all colleges that offer special education in Kenya before it trickles down to primary and secondary schools for the deaf. One of the lecturers said that during the presidential digital talent (DIGITALENT) programme, learners with special needs in special schools were not considered. They were left out. They are in the process to challenge the government and ensure that special learners benefit from it.

\subsection{Learners interview Analysis}

A total of 120 learners were interviewed from 12 schools in western province of Kenya. 10 learners were randomly sampled from each school. The following were the analyzed statistics.

Table 2. Distribution Table showing analysis from learners' interviews

\begin{tabular}{|l|l|l|}
\hline Item & Distribution & Percentage \\
\hline Number interviewed & 120 & 100 \\
\hline Number seen computers & 110 & 91.7 \\
\hline $\begin{array}{l}\text { Number ever used } \\
\text { computers }\end{array}$ & 80 & 66.7 \\
\hline $\begin{array}{l}\text { Presence of computers in } \\
\text { school }\end{array}$ & 89 & 74.2 \\
\hline $\begin{array}{l}\text { Teachers use computer to } \\
\text { teach }\end{array}$ & 20 & 16.7 \\
\hline $\begin{array}{l}\text { Require Computer aided } \\
\text { education }\end{array}$ & 120 & 100 \\
\hline
\end{tabular}




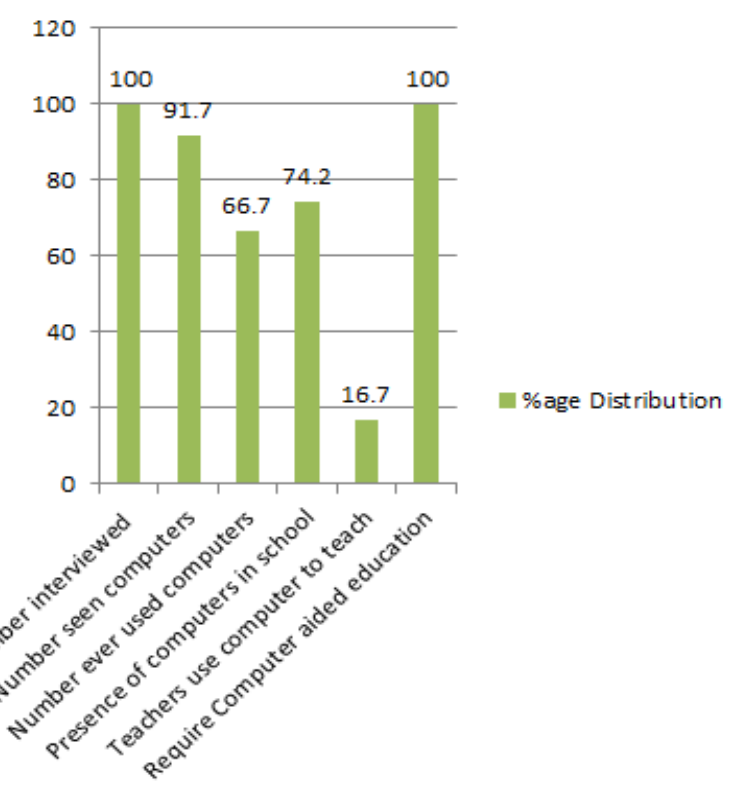

\section{PROPOSED FRAMEWORK}

Two broad categories of assistive technology (AT) have been used to develop this framework, namely: KSL Gesture Recognition System (K-GRS) and KSL computer aided learning and training System. These two technologies enhance communication support for deaf learners and their teachers. It aims at improving conversation and understandability between deaf learners and their teachers. The flowchart below gives an overview of the framework.

Figure 2. Graph showing analysis from learners' interviews

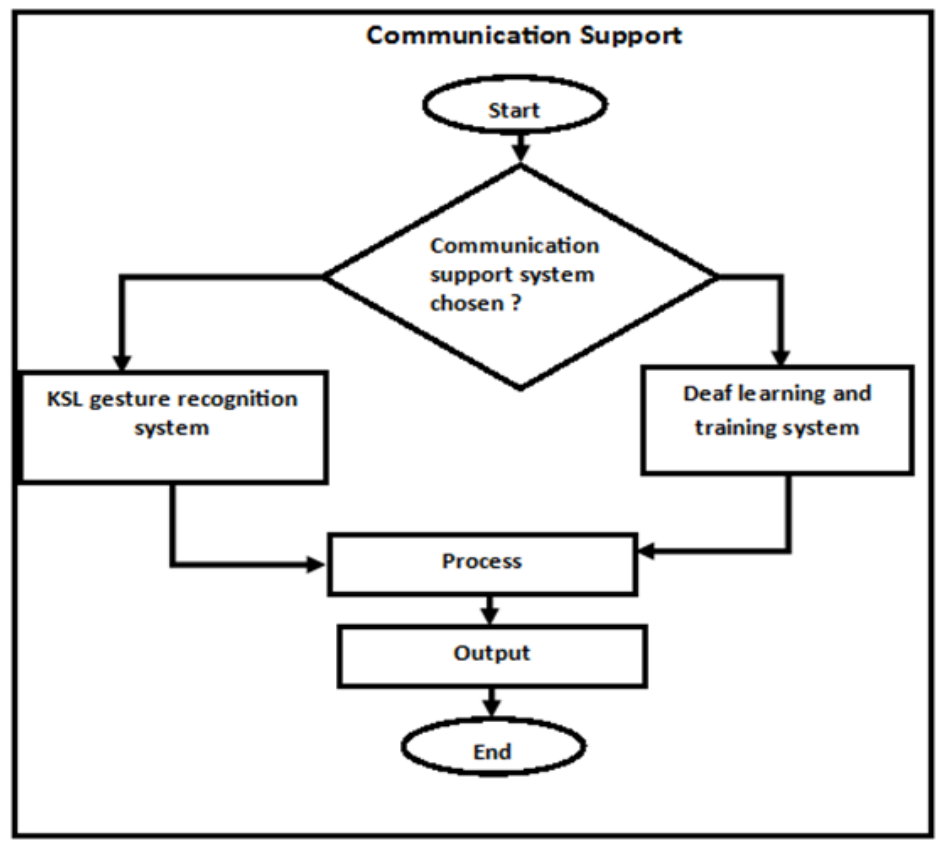

Figure 3. Communication Support flowchart

From the above flowchart, depending on what the user wants to do, he/she can choose one of the two systems: gesture recognition system or KSL learning and training system. KSL gesture recognition system deals mainly with two or more people communicating instantly. One person must be interacting with the system as the other looks on to see output from the monitor. It is purely dynamic. There are many conversions that take place with this system as we shall describe below. Deaf learning and training system is both dynamic and static basing on the mode of use the user chooses to apply.

\subsection{KSL Computer Aided Deaf Learning and Training System}

This system involves applications that can be used for learning purpose. Applications involve real learning contents for deaf learners. The interfaces are slightly different basing on the permissions set for teachers and deaf learners. What the teachers see is different from what the deaf learners see. What teachers can do with content applications, deaf learners cannot do it because of the permissions. This system has been put into two categories or interfaces as shown in the flowchart below. 


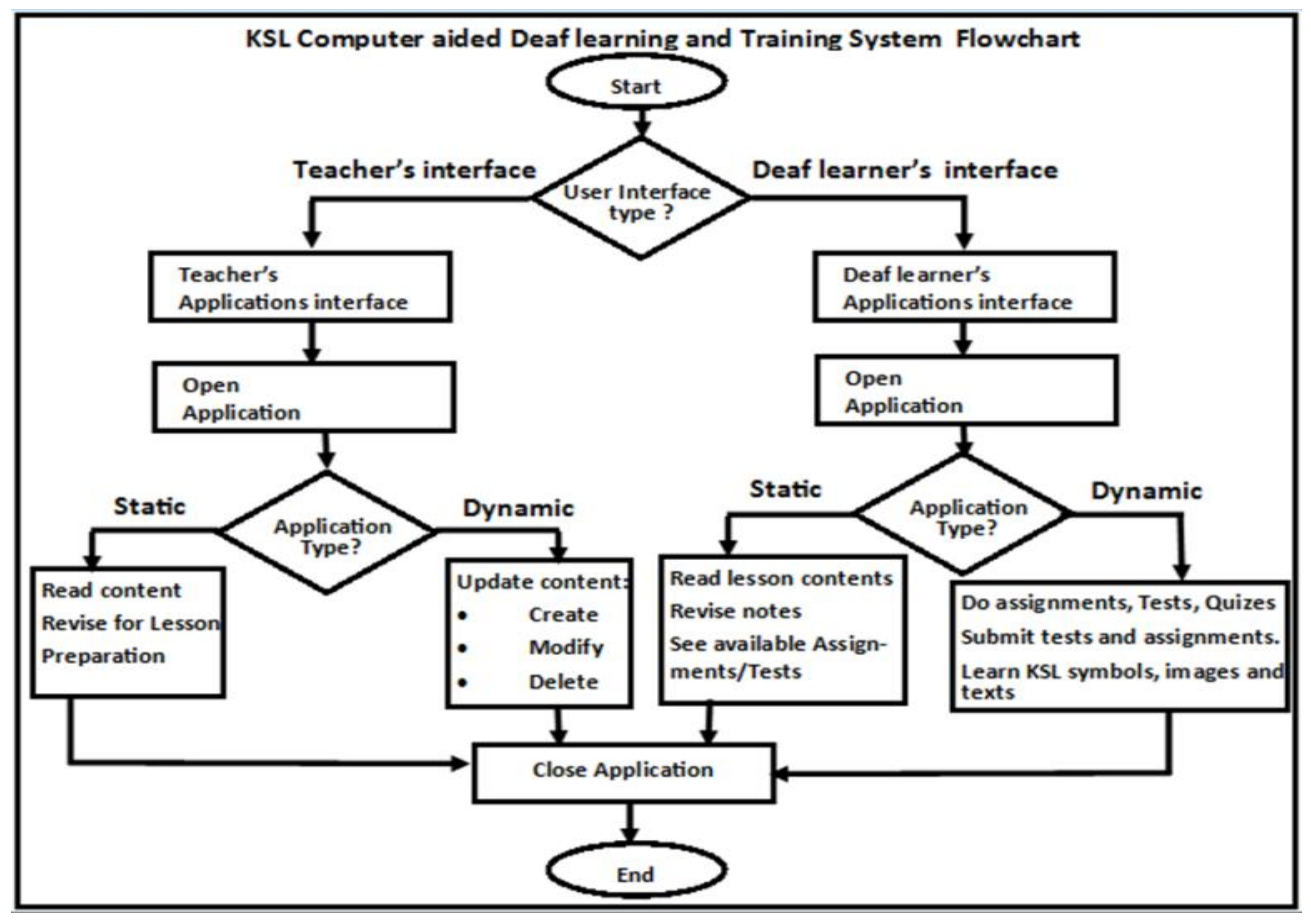

Figure 4. Flow chart for computer aided deaf learning training system

\subsubsection{Teacher's Application Interface}

In this interface, teachers for deaf learners can choose to use either static or dynamic application mode type. In static application mode, teachers for deaf learners can read the already available subject contents in the system; revise contents for their own lesson preparations. In the dynamic application mode, they can create their own contents, modify the already available contents and delete what they do not want from the system. Contents include texts, images and animations. They can also manage assignments, tests and examinations in the system. Teachers interface gives them more permission to change how they want the content to look like.

\subsubsection{Deaf learner's Application Interface}

Deaf learner's application interface allows deaf learners to interact with the system using two application modes; Static and dynamic. In static mode, deaf learners have minimal permission. They can open applications and read subject contents, revise notes for various subjects, learn KSL, see available assignments and use signed KSL dictionary for reference purpose. In the dynamic application mode, deaf learners have permission to do and submit their assignments and tests, learn KSL symbols, texts and images.

The picture below describes an overview of the expected learning and training system for deaf learners

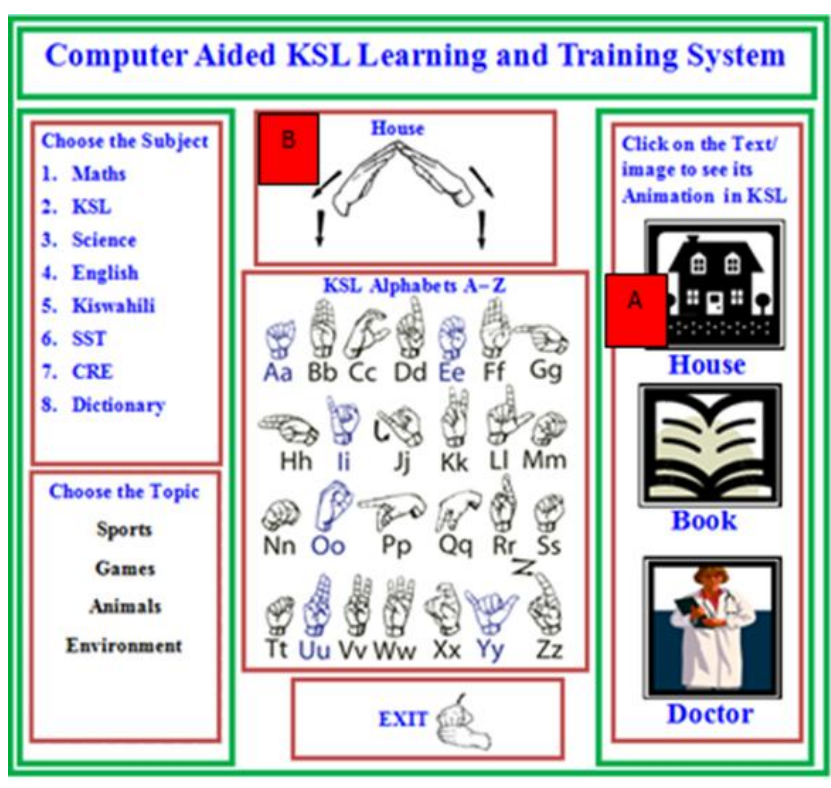

Figure 5. System prototype overview

The learner clicks on the image or text at say point A (for instance; House). The corresponding KSL animation is shown at point B. Learners can choose a variety of subjects, topics, Images, signed dictionary, KSL alphabets, vowels and many more. The system should cover the entire syllabus for deaf learners. The Entire dictionary should be signed. The user should be able to exit after using the system.

The flow chart below describes what happens when text/image is clicked and how the corresponding animation is displayed on the monitor. 
Text to animation conversion flowchart
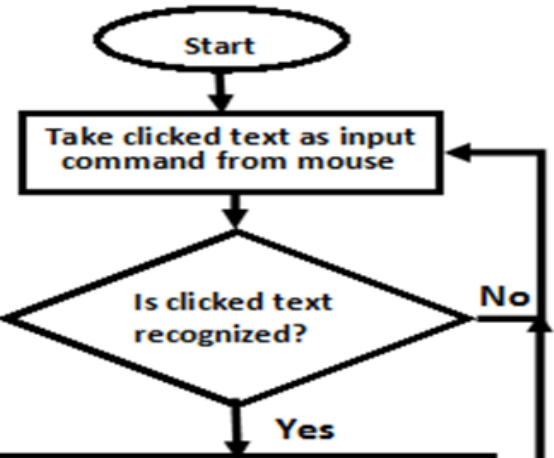

Match clicked text with stored

animations in database

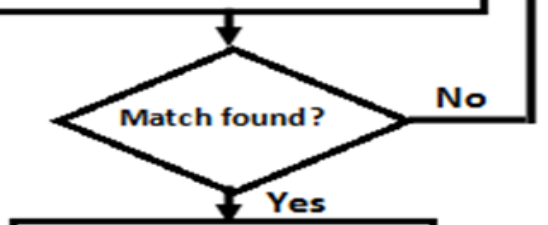

Generate \& display

corresponding animation

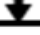

End

Figure 6. Flowchart showing text to animation conversion

The block diagram below (Fig. 7) describes how clicked text/image is converted to a video animation for deaf learners.

When a text/image is clicked, the command is sent to text to animation converter which compares the available text/images in the store text-animation database. If the match is found, it is retrieved and displayed on the monitor.

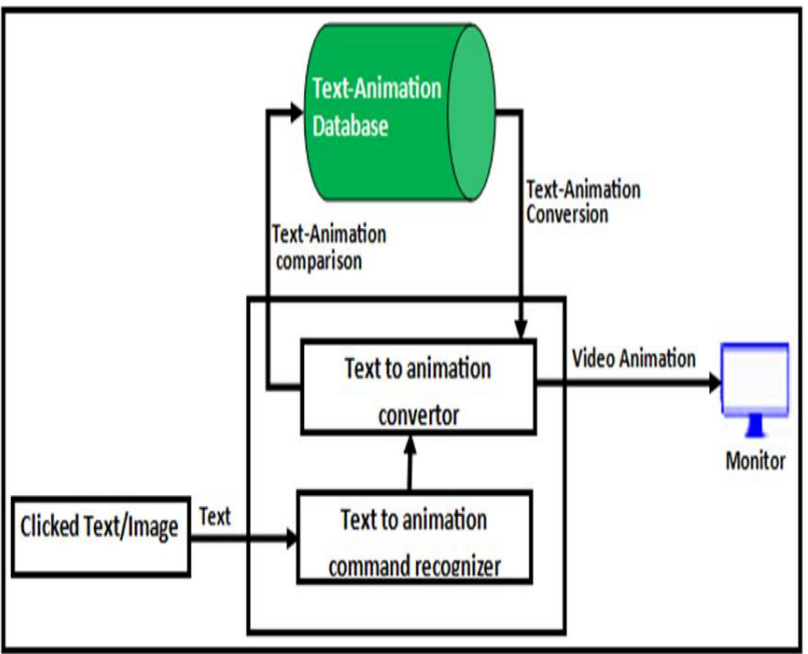

Figure 7. Block diagram for text to animation conversion

\subsection{KSL Gesture Recognition System}

Gesture recognition is the process of understanding and interpreting meaningful movements of hands, arms, face, and head.

The operation of KSL is purely based on gestures. The body and hands play vital role in KSL communications and as a result the following five parameters make up a complete KSL communication system.

a) Movement: This involves frequent movement of body and hands.

b) Hand shape: This describe state of fingers of the person communicating;

c) Palm orientation: This describes the position of the palm of the signer. The palm can either face the audience or away from the audience.

d) Facial expressions: This describes signer's different facial outlooks. Sadness or happiness can be determined by facial expression.

e) Location: This describes location of hands of the communicator. He can position then above the head, before the chest, below the chin or anywhere.

This system captures conversation from two sides; a deaf person showing signs and a non-deaf person speaking.

The system consists of two modes; translation mode and communication mode.

Translation mode converts sign language of a deaf person into text or speech format that can be understood by a non-deaf person. By tracking position of the user's hands, many signs can be recognized instantly by the use of 3D trajectory matching algorithm.

In a communication mode, a normal person communicates with the signer through avatar. He/She speaks to the system through the microphone, the system processes and the avatar sign what he/she says. Microsoft's Kinect sensor for Xbox 360 is used. The diagram below illustrates it.

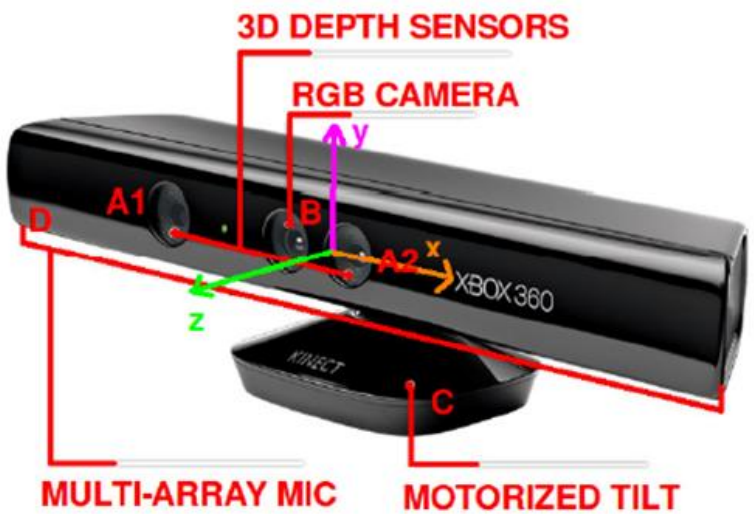

Figure 8. Kinect sensor 


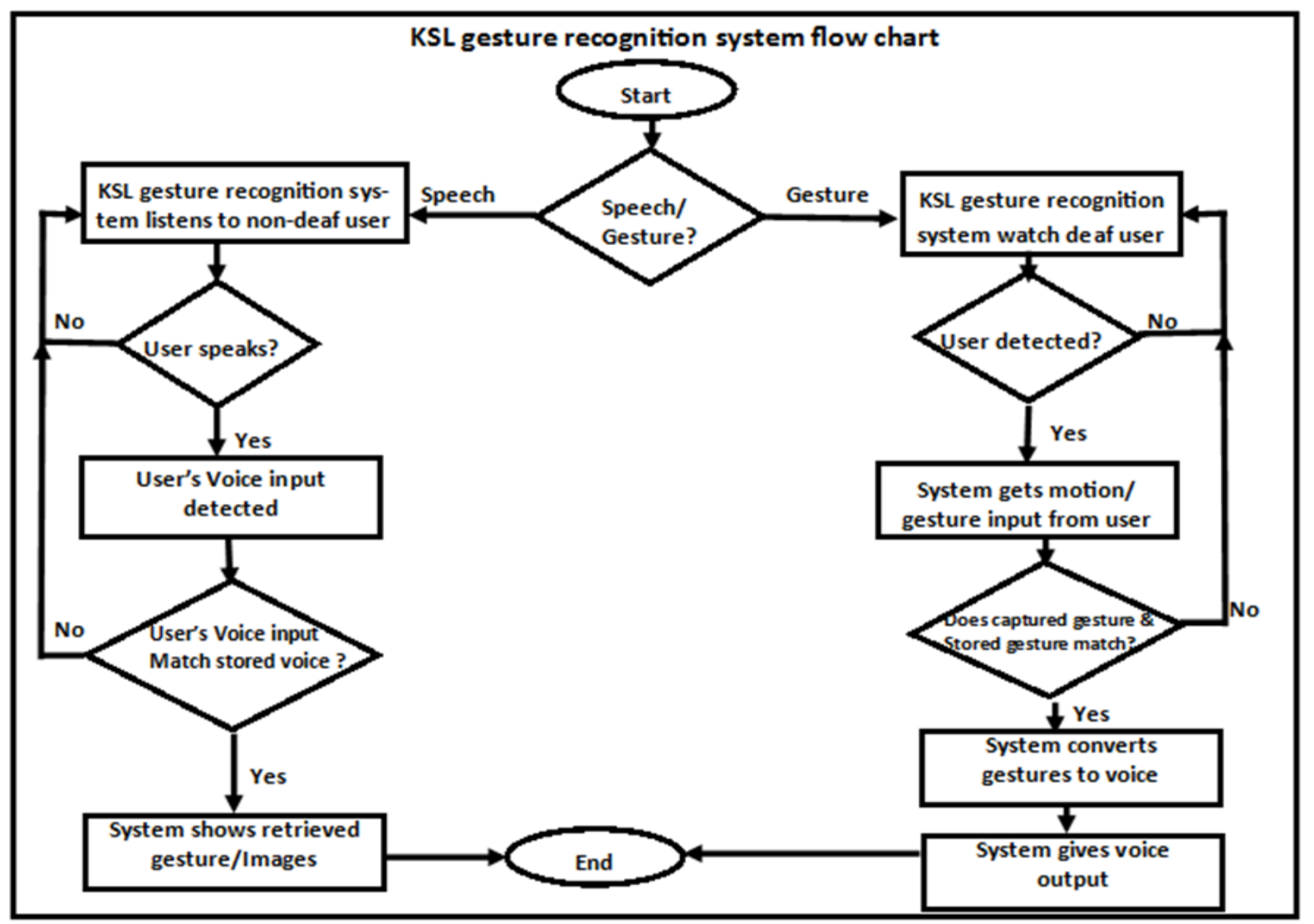

Figure 9. KSL Gesture recognition system flowchart

In the flowchart above (Fig. 9), the user can be either a deaf learner or a teacher (a non-deaf user). KSL gesture recognition system listens to a non-deaf user (for instance a teacher) when he/she speaks. His/her voice is detected and used as an input to the database. A comparison is done between the stored voice gestures in the database and the detected voice. If a match is found, system retrieves and displays detected gesture/image on the screen/monitor. On the other hand, KSL gesture recognition system watch gestures of a deaf learner. It detects his/her body and hand motions and compares with the stored gesture. If a match is found, the system converts gestures to its corresponding

The Kinect sensor has the following components:

1. 3-D depth sensors Three-dimensional sensors track your body within the play space.

2. RGB camera An RGB (red, green, blue) camera helps identify you and takes in-game pictures and videos.

3. Multiple microphones An array of microphones along the bottom front edge of the Kinect sensor are used for voice recognition and chat

Motorized tilt: A mechanical drive in the base of the Kinect sensor automatically tilts the sensor head up and down when needed.

The flowchart below gives an overview of the entire KSL gesture recognition system.

voice. The system then gives the voice output through the speakers.

The block diagram below (Fig. 10) gives a general description of the operation of KSL gesture recognition system.

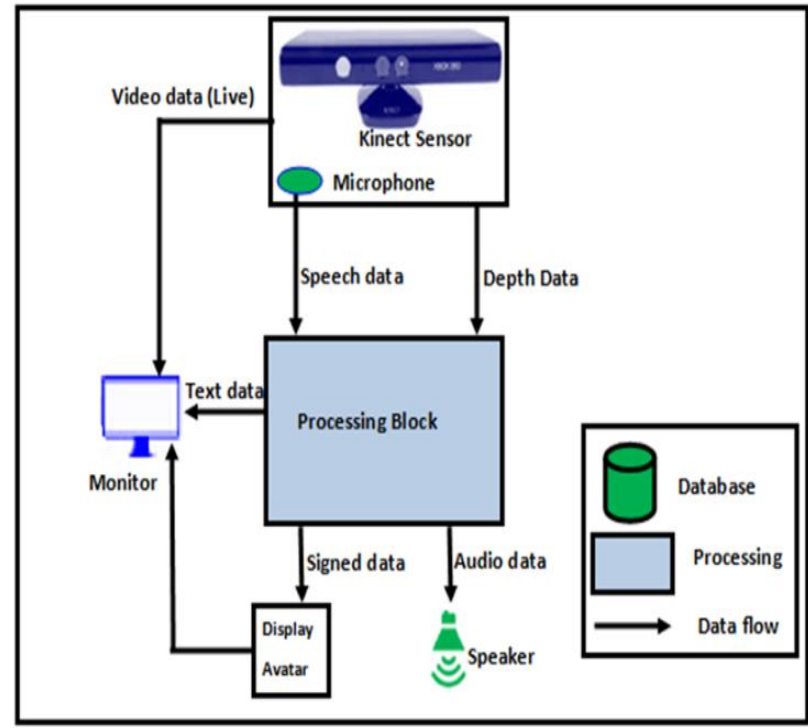

Figure 10. KSL System block diagram

\subsubsection{KSL System}

The inputs to the processing block are: Kinect depth data, live video stream, and speech data.

Depth data contains information which is important for detecting signs together with their meaning.

The speech data originates from the Kinect's microphone. It translates what the normal person says to signs, so that the deaf person can communicate with them. These signs are then sent to the display avatar, which displays on to the monitor. 
Video stream goes to the monitor and displays the interface, which is a live video stream of the person signing into the Kinect. The live video stream shows the signer live feed and shows the signer that what he/she is signing is being processed correctly by the system.

\subsubsection{Processing Block}

The processing module is split into 3 sub-modules.

The recognition module takes in depth data from Kinect and converts it into English text. Data from recognition module goes to two components; text to speech module and monitor.

Output from Text to speech module is audio which is equivalent to text input.

The last module here is speech interpreter module which inputs speech data from the Kinect microphone, converts it to sign data, and pass it to display avatar.

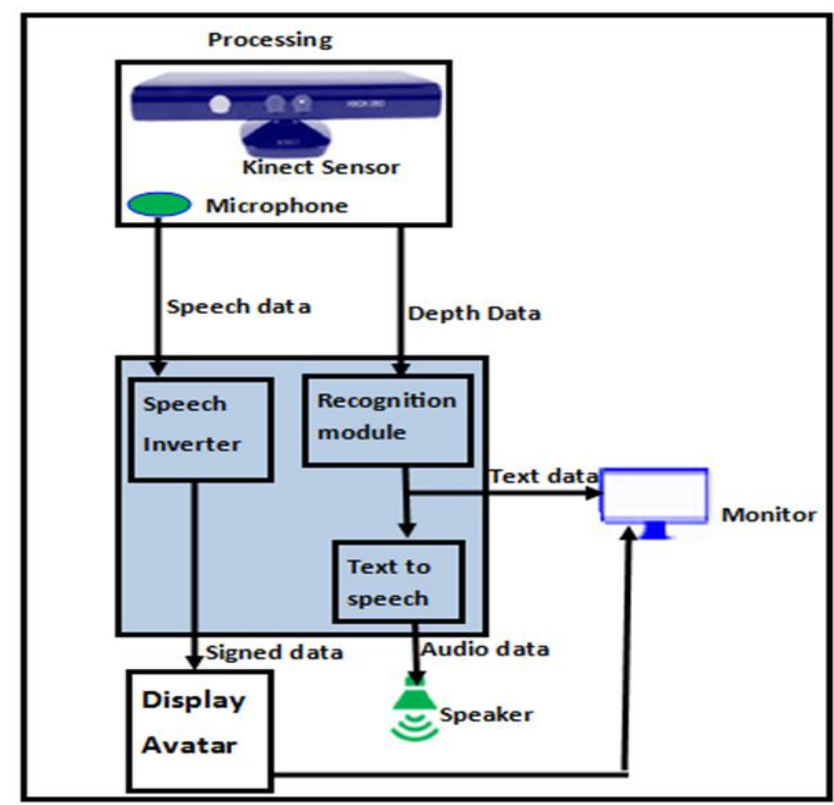

Figure 11. Processing Module Block diagram

\subsubsection{Recognition Module}

Depth data is taken as an input to recognition module. Recognition module interprets depth data by the help of five classification parameters of KSL signs discussed above. These five KSL parameters are: hand shape analysis, movement analysis, location analysis, facial expression recognizer and palm orientation. These parameters translate what the hearing impaired person is signing into the correct meaning. These parameters are passed to the sign identifier module, which queries the sign database to identify potential signs. Sign identifier module selects most likely meaning of the KSL parameters from the results of the sign database. Recognized gesture then goes to sign to text converter module. Here, the sign database is queried for equivalent text of the recognized gesture. The result (text) is then output to both text to speech module, and monitor. The monitor displays interface with the text for which the sign was recognized to mean. The database here must contain each sign/phrase for the sign database to have all the meanings.
The diagram below gives a summary of the description of the recognition module.

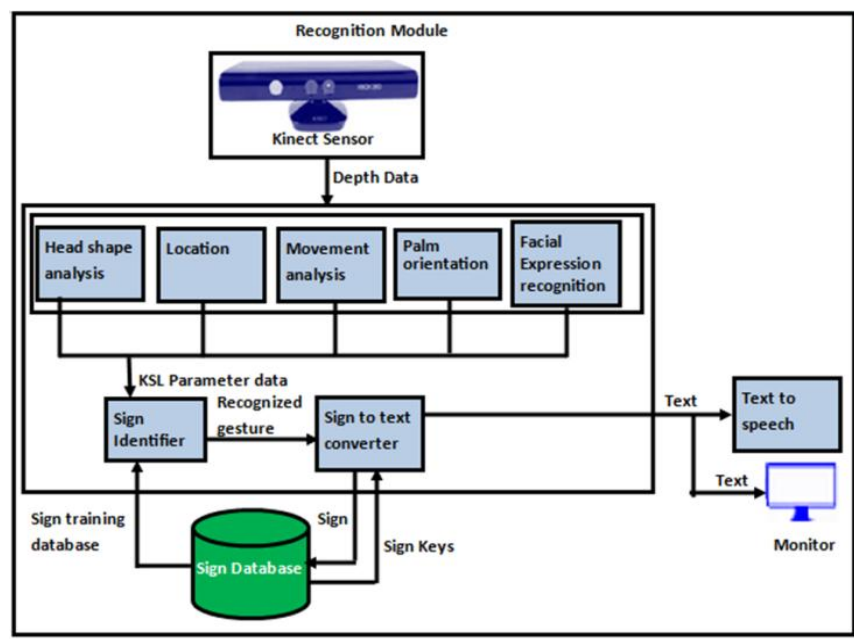

Figure 12. Block Diagram for recognition module

\subsubsection{Text to Speech Module}

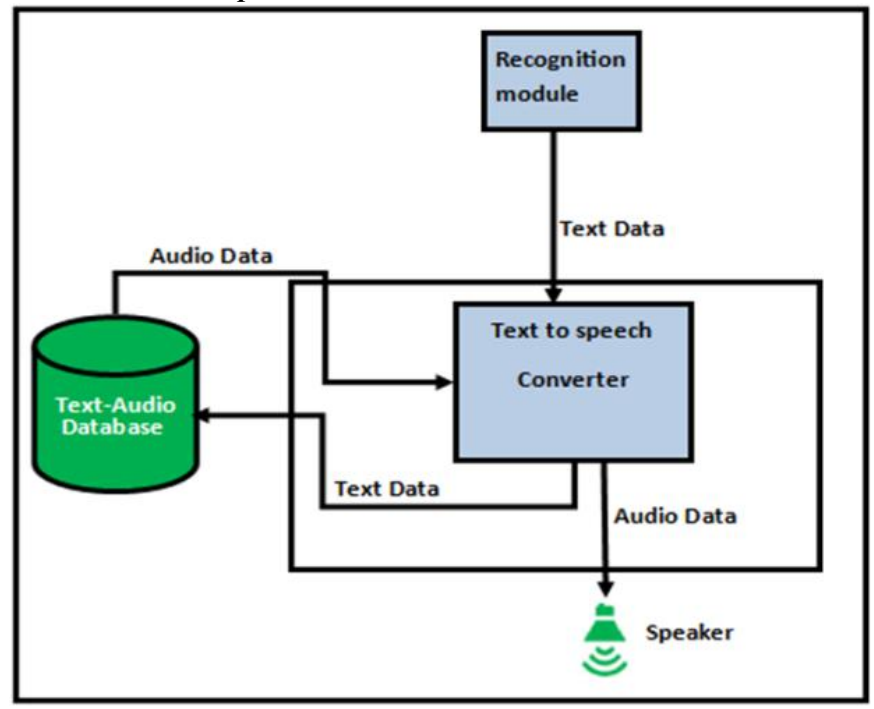

Figure 13. Text to Speech module block Diagram

This module gets text from recognition module. The text then goes to text to speech converter. This then queries the database for the equivalent audio of text. There are a number of text to speech software that can translate text to speech. Some of these are Ivona, Natural Reader, Zabaware Text to Speech Reader, iSpeech, Acapela Group Virtual Speaker among others. The database will use one of these to translate the text to the correct audio. The audio can take on many different voice such as child's, man's or a woman's voice. The detected audio is then sent to the speaker to be heard by the non-impaired person. The normal person can then understand what the deaf person signed. 


\subsubsection{Speech Interpreter Module}

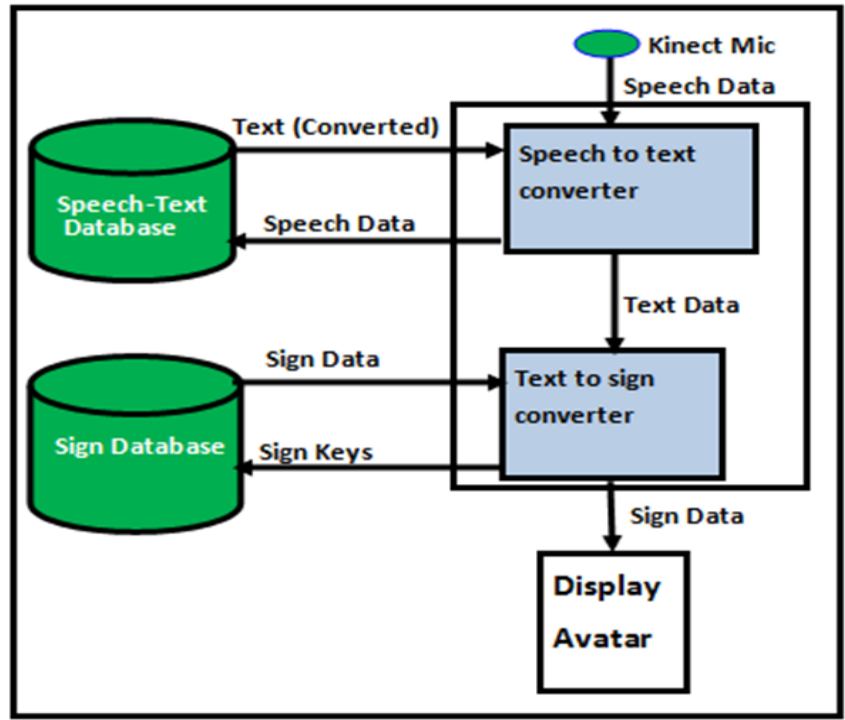

Figure 14. Speech interpreter module diagram

This module receives speech data (audio) from the Kinect's microphone. Data then goes to speech to text converter. The speech to text database is then queried by the converter for the equivalent text of the speech data. The converted text is then sent to text to sign converter, which queries the sign database for equivalent sign of the text. Sign keys are identified in the text with equivalent representation in the sign language. The detected sign data is then sent to the display avatar.

\subsubsection{Display Avatar Module}

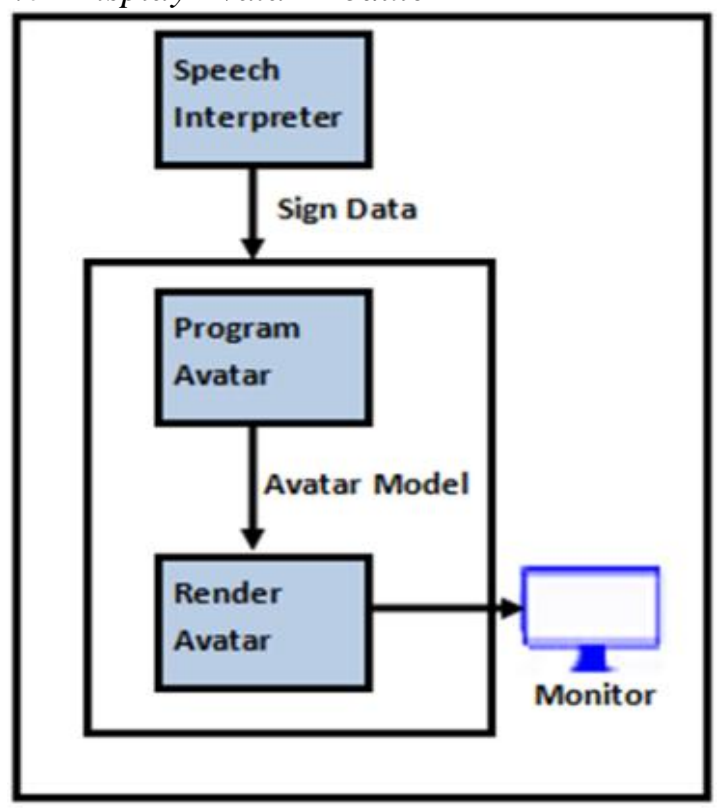

Figure 15. Display Avatar module Block Diagram

The Display Avatar gets output from speech interpreter. The sign data from speech interpreter is then passed to the program avatar module. This then computes the $\mathrm{x}$ and $\mathrm{y}$ coordinates of the hands, and facial expressions for the avatar. With the complete set of $\mathrm{x}$ and $\mathrm{y}$ coordinates and the avatar model created, the avatar model then goes to the Render Avatar module, which displays the avatar onto the monitor.

\section{FRAMEWORK VALIDATION \\ 6.1 System Design}

A prototype of the expected system (simulation) was developed using Visual Basic ((VB 2010) (for interface)) and MYSQL (for database). The system was subjected to various lecturers and students at KISE College for validation. The developed system is basically computer aided KSL learning and training tool. The pictures below shows various captured screenshots of the system used for validation of the framework

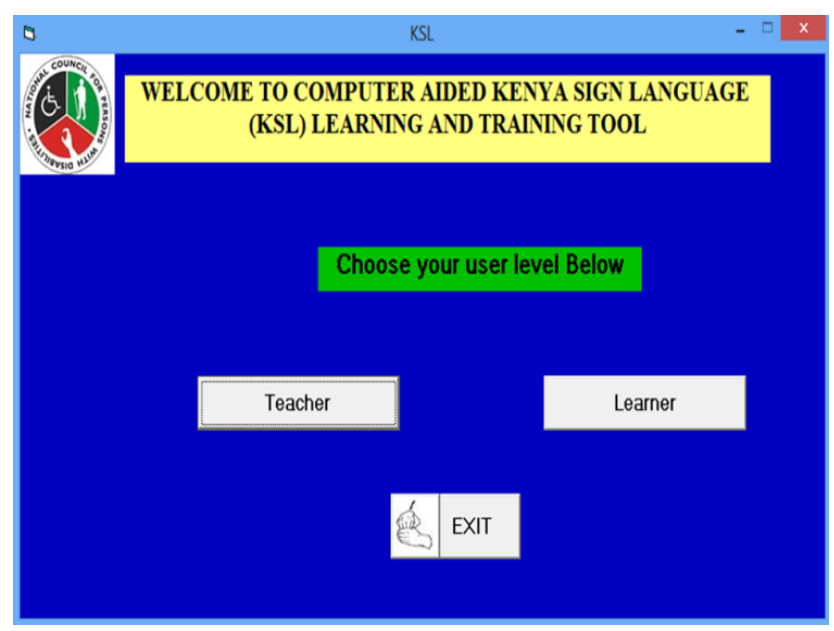

Figure 16. System Switchboard

Upon choosing the user level, the system then offers another interface to interact with the user.

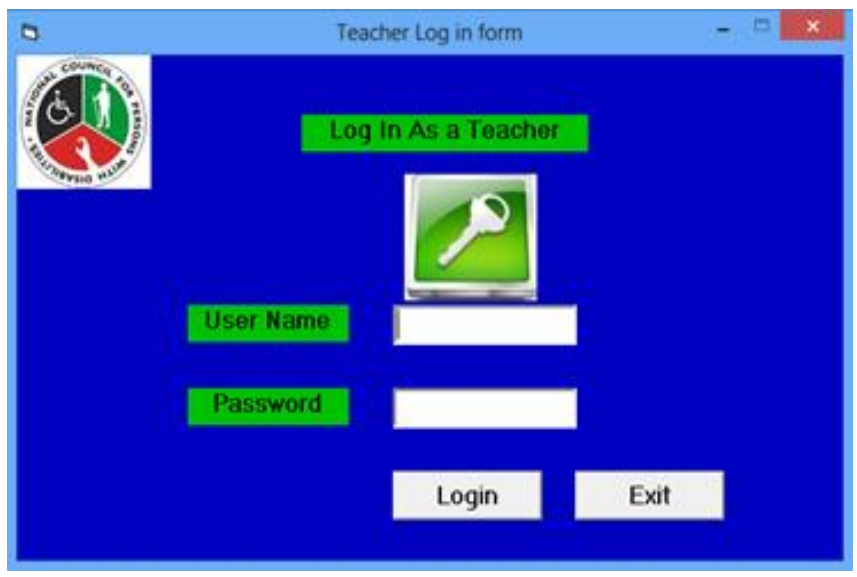

Figure 17. User validation by the system

The interface simply confirms the credentials from a table of 'teacher' users in the system's database. The confirmation then allows the user access the facilities available for teachers. This can be indicated in the figure shown below. 


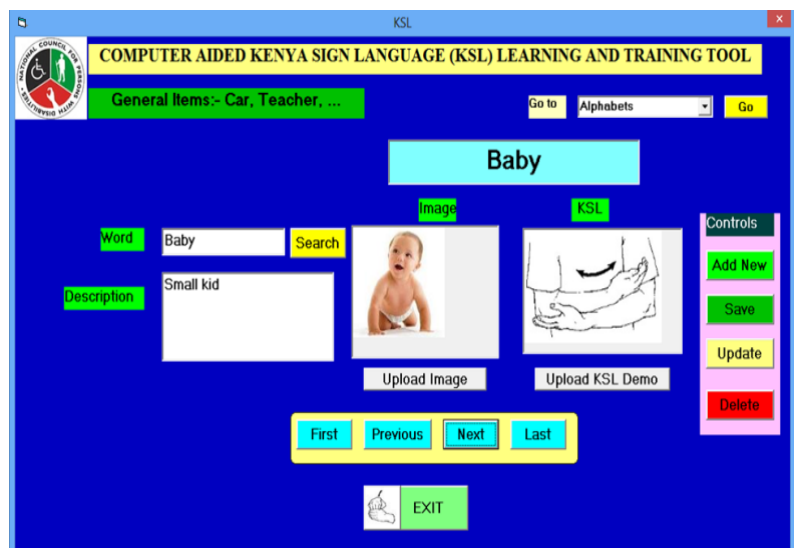

The figure above shows teachers' form for general Items. Teachers have permission to add new items, save them, update, and delete items. The user can also search for specific items, and navigate between item categories (Alphabet, General, numbers etc). The interface allows the teacher to develop a lesson plan and on a subject using visual aids. This form is different from the one accessed by learners.

The learners interface does not have controls such as adding new item, saving updating or deleting items as shown in the figure below.

Figure 18. Teacher user interface form

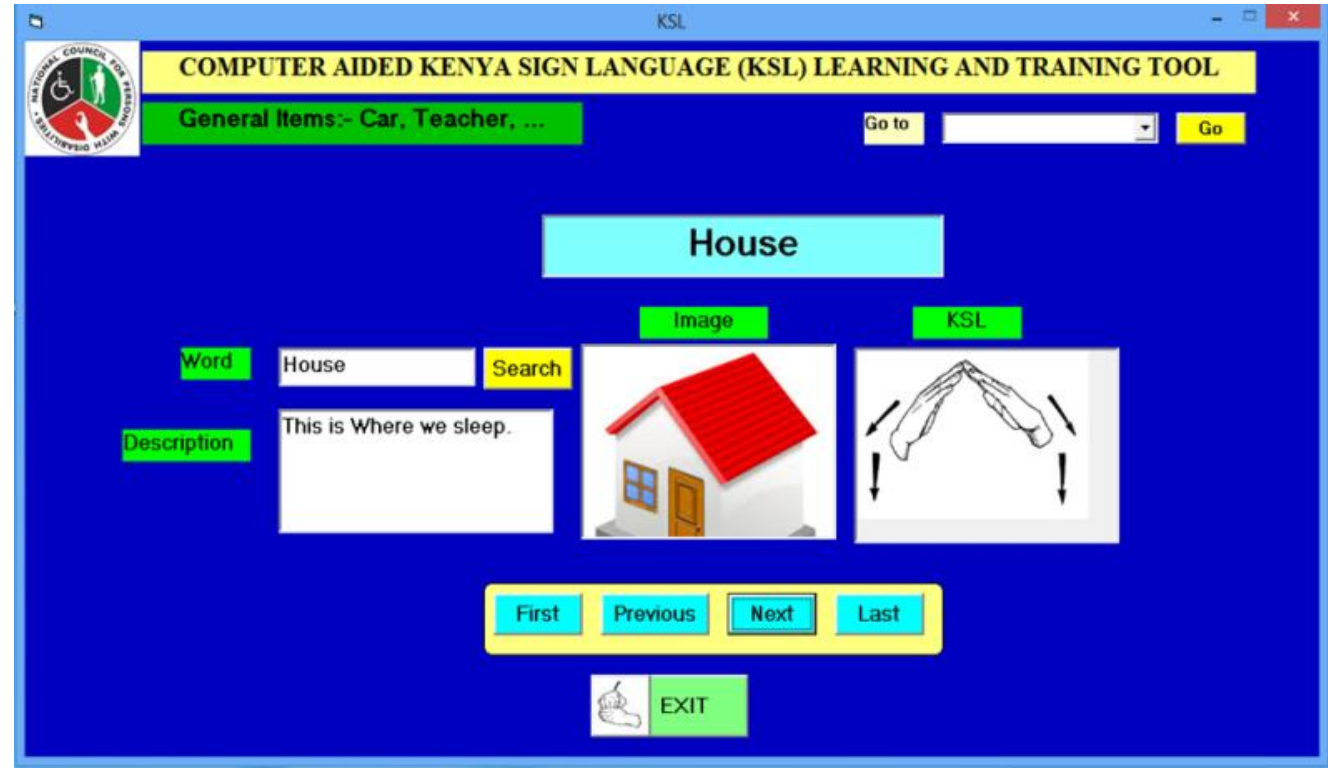

Figure 19. Deaf learner system interface

\subsection{Framework Validation Experiment}

This framework was validated at KISE (Kenya Institute of Special Education) college in Nairobi. Simple random sampling was used to get respondents. A total of 100 respondents (10 lecturers and 90 students) were involved in the validation process. Presentation was done in a class using a projector. After presentation, questionnaires were given to the respondents to fill. The response to each question required either Yes, to some extent or No. The questions responded to were as follows:

1. Does the technology involved in the development of the framework (Assistive Technology) recommend for deaf learners?

2. Are the colors used for the demo recommended for deaf learners?

3. The words, pictures and their corresponding KSL demo are clear and understandable.

4. Can deaf learners be able to use the communication support tools (KSL gesture recognition system and deaf learning and training system) at ease?

5. The developed system if fully implemented can improve learning understandability of a deaf learner.
6. Are the application interfaces used in the system recommendable for both deaf learners and their teachers?

7. Can the developed framework enable effective and interactive learning among deaf learners?

8. All the required KSL parameters (Hand shape, hands location, movement, palm orientation and facial expression) have been captured in the framework and well elaborated.

9. Computer aided KSL learning and training system covers majority of the contents that deaf learners ought to study wile at school.

10. Have you ever used system similar to the one you have interacted with in the course of your study?

11. Generally, if implemented, the framework can serve deaf learners in Kenya.

12. Do you recommend the installation and usage of this system in special schools especially deaf schools in Kenya? 


\subsection{Results}

Majority of the respondents said the system brings out the unique way of teaching and interacting with deaf people. Instructors at KISE College recommended the system to be included in the government program for digital learning in deaf schools such that when pupils in primary schools in Kenya get laptops and digital learning contents, deaf learners should get laptops too and such a system should provide the digital contents for deaf learners.

The captured response data from questionnaires was analyzed and a graphical representation of the information designed as shown in the figure below;

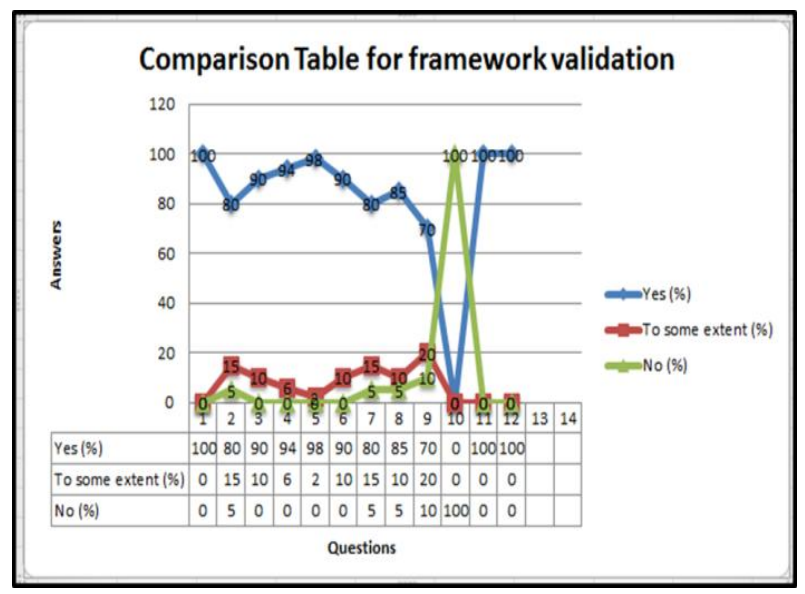

Figure 20. Responses from users on suitability of system use

\section{CONCLUSION AND FUTURE WORK}

The main objective of the research was to develop framework for computer aided education and training for learners with hearing impairment. Assistive Technology was used to develop the framework. The research highlighted the major challenges facing learners with hearing impairment as far as ICT is concerned. The literature review was guided by the objectives of the research. The review of the literature covered areas that included how teachers and learners use available ICT resources for teaching and learning, challenges facing deaf in accessing ICT resources and appropriate frameworks for computer aided learning for the deaf. In the research, both qualitative and quantitative approaches were used through a number of research instruments that included questionnaires and interviews.

The research showed that most schools for the deaf had not committed themselves to utilize ICT in teaching and learning. However in terms of ICT facilities, its connection and accessibility some schools had some foundation in place that can motivate teachers and learners to utilize ICT in their teaching and learning. This research also revealed positive attitude for teachers and learners to use ICT. This in addition to funding by the government is an enabler for ICT integration.

From the results and analysis of this research, the following are the recommendations:

i. Deaf learners and their teachers should improve the training of their ICT skills and knowledge by making it more practical oriented whereby deaf learners should be taught using video lessons with the help of computers and projectors.

ii. KSL should be standardized in all deaf schools in
Kenya. As a result, English dictionary and 'Kamusi' should be signed either by the use of images or computer animations or both and hence their examinations should also be done in KSL and not in English or 'Swahili'.

iii. Since laptops have been introduced in primary schools, I urge the government of Kenya through the ministry of education to adopt this framework for deaf learners.

This research forms the foundation on which other research can be done especially in moving the integration of ICT in education for the deaf from basic levels to further level in all schools for the deaf in the country. Research with similar objectives can be carried out to identify the attitudes and experience of other learners and teachers in institutions with deaf learners in Kenya in ICT integration in teaching and learning events. Further studies should concentrate on moving from introductory level to integration level.

\section{ACKNOWLEDGEMENT}

I appreciate financial support from family members, Fr. Kizito Robert Oloo and Mr. Mugambi Felix.

\section{REFERENCES}

[1] Abo, E., S. \& Samaa, M., S. (2010). Web accessibility framework for the Arab deaf-blind.

[2] Achoka, J. S. K.; Odebero, S. O.; Maiyo J. K. \& Mualuko N. J. (2007). Access to Basic Education in Kenya: Inherent Concerns. Educational Research and Review Vol. 2 (10), pp. 275284.

[3] Balescut, J. \& Eklindh, K. (2006). Historical Perspective on Education for Persons with disabilities. Background Paper for EFA Global Monitoring Report 2006.

[4] Bandhana, B. (2012) Integration of Information and Communication Technologies in Enhancing Teaching and Learning. Contemporary Educational Technology, 3(2), pp 130-140.

[5] Boldyreff, E., B. (2001). The Case for the Use of Plain English to Increase Web Accessibility, 3rd International Workshop on Web Site Evolution IEEE WSE.

[6] Bray, M. \& Varghese, N.V. (2008). Directions in Educational Planning,_Report on an IIEP Symposium. Paris: International Institute for Educational Planning (IIEP).

[7] Chee Kyun N.; Yeong, T., L, M., \& Iqbal S., A., F. (2008). E-Learning System: Disabled Friendly Education System, European Journal of Social.

[8] Clarke, M., \& Kirton, A., (2003). Patterns of interaction between children with physical disabilities using augmentative and alternative communication systems and their peers. Child Language Teaching and Therapy, 19 (2), pp. 135-151.

[9] Detheridge, T. (1997). Bridging the communication gap for pupils with profound and multiple learning difficulties. British Journal of Special Education, 24 (1), pp. 21-26.

[10] Drigas, S., A. (2005). An e-Learning Management System for the Deaf people.

[11] El Ghoul, O., \& Jemni, M. (2009, 11). Multimedia Courses generator for deaf children. The International 
Arab Journal of Information Technology, 6, 458-463.

[12] Elger, G., \& Furugren, B. (1998). SmartBo - An ICT and computer-based demonstration home for disabled people. Improving the quality of life for the European citizen: Technology for inclusive design and equality, 392-395.

[13] Gennari., R., O., M. (2008). Designing and Assessing an Intelligent E-Tool for Deaf Children, Intelligent User Interface Conference (IUI'08).

[14] Harrysson, B., Svensk, A., \& Johansson, G. (2004). How people with developmental disabilities navigate the Internet. Bristish Journal of Special Education, 138-142.

[15] Higgins, E.L.,\& Raskind., M. H. (2000). Speaking to read: the effects of continuous vs. discrete speech on the reading and spelling performance of children with learning disabilities'. Journal of Special Education Technology (JSET). http://jset.unlv.edu/15.1/higgins/ higgins.pdf.

[16] Kirimi, S. \& Munyinyi, W. (2004). Facts on the Economic Recovery Strategy Civil Society Perspective. Nairobi: National Council of NGOs.

[17] Khwaldeh, S.N., \& Matar, Z. (2007). Hunaiti. Interactivity in Deaf Classroom Using Centralized Elearning System in Jordan.

[18] Lanconi, G. (2001). Use of microswitches and speech output systems with people with severe/profound intellectual or multiple disabilities: Research in Developmental Disabilities, 22 (1), pp. 21-40.

[19] Meager, N., Hill, D., \& Wilson, S. (2007). ICT Strategy, disabled people and employment in the UK. Institute for Employment Studies.

[20] Mugo, J.K., Oranga, J. \& Singal, N. (2010) Testing youth transitions in Kenya: Are young people with disabilities falling through the cracks? RECOUP Working paper No.34.Retrieved March 19/3/2013, from http://recoup.educ.cam.ac.uk/publications/disabilitypubli cations.ht.

[21] Murugami, M.W. (2009). Disability and Identity, Ohio State University Libraries. USA.

[22] Nickson, O., K. (2012). Challenges facing deaf in accessing ICT. Nairobi.

[23] Nicoletta, A., \& Martin, Z. (2004). The MathSigner: an Interactive Learning Tool for American Sign Language, Proceeding of the 8th IEEE International Conference on Information Visualization.

[24] Ohene-Djan, J., \& Saduf N. (2005). An Adaptive WWW-based System to teach British Sign Language: Proceeding of the 5th IEEE International Conference on Advanced Learning Technologies (ICALT'05).

[25] Olaniyan, D. A. \& Okemakinde, T. (2008). Human Capital Theory: Implications for Educational Development, Ibadan: EuroJournals Publishing, Inc.

[26] Osundwa, E., (2007). The Employment of Visually Impaired People in Kenya. Paper Presented at the WBU Fourth Africa Forum on Jamii Jumuishi - Social Inclusion, 6-11 May, 2007, Nairobi, Kenya.

[27] Psacharopoulos, G. (1988). Education and Development:
A Review. The World Bank Research Observer 3, no. 1 p 99-116. The International Bank for Reconstruction and Development.

[28] Psacharopoulos, G. (1993). Returns to Investment in Education. A Global Update. The World Bank WPS 1067.

[29] Psacharopoulos, G. (1994). Return to investment in education: A global update. World Development 22 (9), $1325-1343$

[30] Psacharopoulos, G. (1984). Assessing Training Priorities in Developing Countries: Current Practice and Possible Alternatives. International Labour Review 123, no. 5: $569-83$.

[31] Republic of Kenya, (2007). Statistical Abstract. Nairobi: Kenya National Bureau of Statistics.

[32] Republic of Kenya, (2008). The Development of Education. National Report of Kenya Ministry of Education. Nairobi: Government Printer.

[33] Republic of Kenya, (2008) Kenya National Survey for Persons with Disabilities Preliminary Report. National Coordinating Agency for Population and Development (NCAPD) Government Printer. Nairobi.

[34] Republic of Kenya, (2009). The 2009 Population and Housing Census Results. Nairobi: Office of the Prime Minister Ministry of State for Planning, National Development and Vision 2030, Government Printer.

[35] Seymour, W., \& Mackinson, A. (2004). ICTs and disability: exploring the human dimension of the technological engagement. ICTs \& Inequalities: the digital divides (pp. 1-18). Paris: Carre des Sciences.

[36] Shirali-Shahreza, M. (2008). Encouraging Persons with Hearing Problem to Learn Sign Language by Internet Websites. 8th IEEE International Conference on Advanced Learning Technologies (ICALT).

[37] Stewart, D. (2007) "American Sign Language (ASL) Browser", Michigan State University, May 2007.Available:http://commtechlab.msu.edu/sites/aslweb

[38] UNESCO, (1990). World Declaration on Education for All. Adopted by the World Conference on Education for All Meeting Basic Learning Needs. Jomtien: Published by UNESCO for the Secretariat of the International Consultative Forum on Education for All.

[39] UNESCO, (2003). EFA Global Monitoring Report 2003/4. Gender and Education for All: The Leap to Equality. Paris: UNESCO.

[40] UNESCO, (2005). United Nations Decade of Education for Sustainable Development. UNESCO Education Sector.

[41] UNESCO, (2008). Background paper prepared for the Education for All Global (EFA) Monitoring Report 2009. Four Studies of Education Growth: Inequality by wealth, Age effects, Sub-national learning differentials, and Projections Education Policy and Data Center. UNESCO

[42] UNESCO, (2010). National Education Support Strategy (UNESS) for the Republic of Kenya 2010 - 2011. Special Needs Education. Nairobi: Kenya 